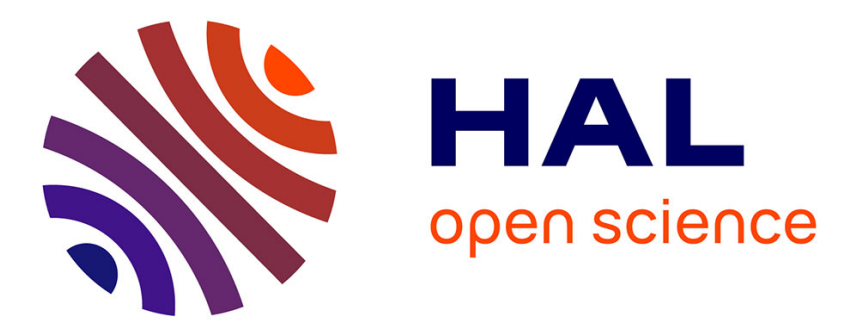

\title{
The ups and downs of beta oscillations in sensorimotor cortex
}

Bjørg Elisabeth Kilavik, Manuel Zaepffel, Andrea Brovelli, William A Mackay, Alexa Riehle

\section{- To cite this version:}

Bjørg Elisabeth Kilavik, Manuel Zaepffel, Andrea Brovelli, William A Mackay, Alexa Riehle. The ups and downs of beta oscillations in sensorimotor cortex. Experimental Neurology, 2013, 245 (15-26), 10.1016/j.expneurol.2012.09.014 . hal-01464144

\section{HAL Id: hal-01464144 https://hal-amu.archives-ouvertes.fr/hal-01464144}

Submitted on 16 Feb 2017

HAL is a multi-disciplinary open access archive for the deposit and dissemination of scientific research documents, whether they are published or not. The documents may come from teaching and research institutions in France or abroad, or from public or private research centers.
L'archive ouverte pluridisciplinaire HAL, est destinée au dépôt et à la diffusion de documents scientifiques de niveau recherche, publiés ou non, émanant des établissements d'enseignement et de recherche français ou étrangers, des laboratoires publics ou privés. 
Review

\title{
The ups and downs of beta oscillations in sensorimotor cortex
}

\author{
Bjørg Elisabeth Kilavik ${ }^{\mathrm{a}, *, 1}$, Manuel Zaepffel ${ }^{\mathrm{a}, 1}$, Andrea Brovelli ${ }^{\mathrm{a}}$, William A. MacKay ${ }^{\mathrm{b}}$, Alexa Riehle ${ }^{\text {a }}$ \\ a Institut de Neurosciences de la Timone (INT), CNRS and Aix-Marseille University, Marseille, France \\ ${ }^{\mathrm{b}}$ Department of Physiology, University of Toronto, Toronto, Ontario, Canada
}

\section{A R T I C L E I N F O}

\section{Article history:}

Received 31 May 2012

Revised 12 September 2012

Accepted 20 September 2012

Available online 27 September 2012

\section{Keywords:}

Beta oscillations

Sensorimotor cortex

Human EEG

Monkey LFP

\begin{abstract}
A B S T R A C T
Since the first descriptions of sensorimotor rhythms by Berger (1929) and by Jasper and Penfield (1949), the potential role of beta oscillations $(\sim 13-30 \mathrm{~Hz})$ in the brain has been intensely investigated. We start this review by showing that experimental studies in humans and monkeys have reached a consensus on the facts that sensorimotor beta power is low during movement, transiently increases after movement end (the "beta rebound") and tonically increases during object grasping. Recently, a new surge of studies exploiting more complex sensorimotor tasks including multiple events, such as instructed delay tasks, reveal novel characteristics of beta oscillatory activity. We therefore proceed by critically reviewing also this literature to understand whether modulations of beta oscillations in task epochs other than those during and after movement are consistent across studies, and whether they can be reconciled with a role for beta oscillations in sensorimotor transmission. We indeed find that there are additional processes that also strongly affect sensorimotor beta oscillations, such as visual cue anticipation and processing, fitting with the view that beta oscillations reflect heightened sensorimotor transmission beyond somatosensation. However, there are differences among studies, which may be interpreted more readily if we assume multiple processes, whose effects on the overall measured beta power overlap in time. We conclude that beta oscillations observed in sensorimotor cortex may serve large-scale communication between sensorimotor and other areas and the periphery.
\end{abstract}

(c) 2012 Elsevier Inc. All rights reserved.

\section{Contents}

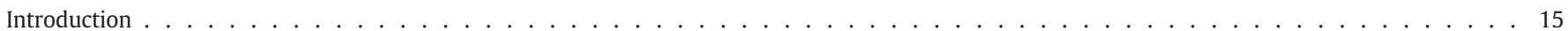

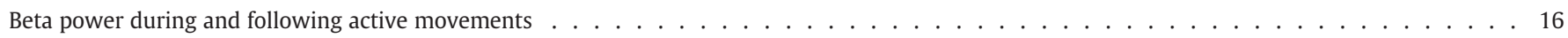

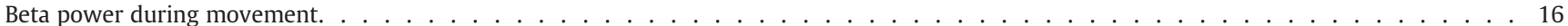

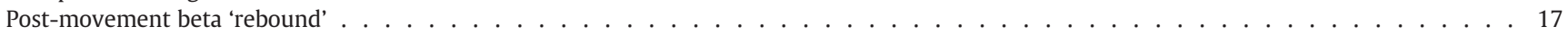

Beta power during static hold . . . . . . . . . . . . . . . . . . . . . . . . . . . . . . . 18

Beta power in earlier epochs of delay tasks . . . . . . . . . . . . . . . . . . . . . . . . . . . . . . . 18

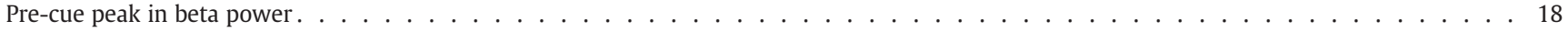

Post-cue decrease in beta power . . . . . . . . . . . . . . . . . . . . . . . . . . . . . . 20

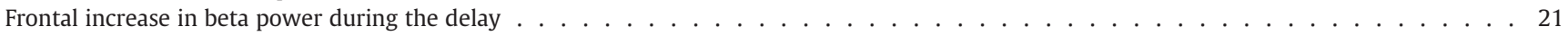

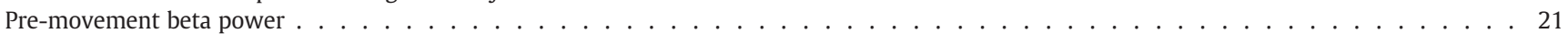

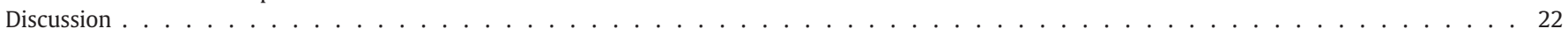

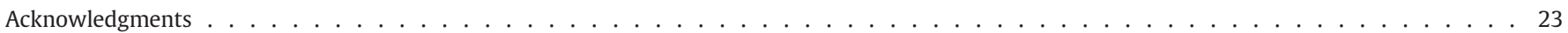

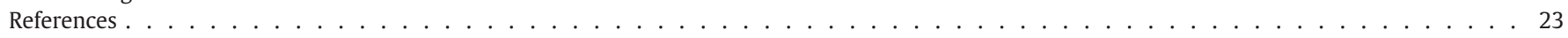

\section{Introduction}

It is a great pleasure to dedicate this review to Prof. J. Dostrovsky, whose research career encompassed both the somatosensory system

\footnotetext{
* Corresponding author at: Institut de Neurosciences de la Timone (INT), CNRS Aix-Marseille Univ., Campus Santé Timone, 27, bd Jean Moulin, 13385 Marseille cedex 5, France. Fax: + 334913240 56x57.

E-mail address: bjorg.kilavik@univ-amu.fr (B.E. Kilavik).

1 Authors contributed equally.
}

and oscillatory signals in motor areas, two fields for which there is increasing evidence of a connection. In the present work, we focus on beta frequency-band oscillations $(\sim 13-30 \mathrm{~Hz})$ in sensorimotor cortex, which have been intensely investigated since their first descriptions by Berger (1929) and by Jasper and Penfield (1949). Beta oscillations in scalp electroencephalographic (EEG) and intra-cortical local field potential (LFP) signals are primarily observed over the central 'Rolandic' areas (sensorimotor cortex). They are more prominent during sensorimotor processes than relaxed states (MacKay and Mendonça, 1995; Takahashi et al., 2011), and during motor behavior they display minimal 
power during movement periods and high power during postural maintenance, such as during stable object hold (e.g., Baker et al., 1997; Conway et al., 1995; Spinks et al., 2008).

In general, power modulations in brain oscillations may be related to the degree of spike synchronization (Denker et al., 2011) and/or the overall level of activity in neuronal populations (Nauhaus et al., 2009). Furthermore, the oscillation frequency may be related to the extent of neuronal networks (Kopell et al., 2000; Miller, 2007; von Stein and Sarnthein, 2000) or the underlying excitation-inhibition balance (Brunel and Wang, 2003; Buzsáki, 2006; Jensen et al., 2005; Ray and Maunsell, 2010; Whittington et al., 2000). Oscillations at different frequencies may therefore reflect different neuronal populations and/ or network states. Beta oscillations are no exception and they can synchronize over large networks, spanning multiple cortical (Brovelli et al., 2004; Murthy and Fetz, 1992, 1996; Roelfsema et al., 1997) and sub-cortical (Courtemanche and Lamarre, 2005; Courtemanche et al., 2003) areas.

Despite the ubiquitous presence of brain oscillations, it is still disputed whether they are merely a by-product of brain activity or rather serve specific functions. Indeed, several functional roles are proposed for beta oscillations. On the one hand, beta oscillations have been linked to top-down control (Buschman and Miller, 2007; Siegel et al., 2012) and heightened visuomotor attention (Classen et al., 1998; Roelfsema et al., 1997). On the other hand, it has been proposed that beta oscillations reflect an active process promoting the existing motor or cognitive states (i.e. "status quo") (Engel and Fries, 2010), a notion partly inspired by a previous hypothesis viewing the beta rhythm as a marker of an "idling" state of the motor system (Jasper and Penfield, 1949; Pfurtscheller et al., 1996).

How can these notions be reconciled with the well-described behavior of beta oscillations in sensorimotor cortex during movements and stable postures? We suggest that recent neurophysiological studies using novel sensorimotor task designs in human and non-human primates provide original experimental evidence that may lead to a better understanding of the functional role of beta oscillations. Overall, these studies introduced previously unexplored task epochs, such as those preceding and following a cue presentation and leading up to the GO signal (see Fig. 1A), as well as introducing additional task requirements beyond movement execution, such as signal processing and short-term memory (Fig. 1B). In the present review, we will first describe how beta oscillatory power in sensorimotor cortex modulates during and following movement, and during stable object hold. In a second part, we will seek to understand whether modulations in sensorimotor beta power in task epochs other than during and after movement are consistent across studies, and discuss how these complementary experimental approaches support or contradict different hypotheses regarding the role of beta oscillations in sensorimotor cortex and beyond.

While we restrict this review to the sensorimotor cortex, it is clear that important subcortical structures, including the basal ganglia, are functionally interconnected with the cortex and intimately involved in sensorimotor integration and motor control. Consistent with this, many of these structures feature beta oscillations that modulate with sensorimotor behavior and are coherent with cortical beta oscillations (e.g. Alavi et al. 2013-this issue; Cassim et al., 2002; Courtemanche et al., 2003; Fogelson et al., 2006; Jenkinson and Brown, 2011; Klostermann et al., 2007; Lalo et al., 2008; Litvak et al., 2011; Marsden et al., 2001; Tsang et al., 2010, 2012). The cortico-subcortical loops during sensorimotor behavior, which may be reinforced by coherent beta oscillations cover a field of research and would clearly exceed our review topic.

\section{Beta power during and following active movements}

\section{Beta power during movement}

Beta power in sensorimotor tasks is lowest during movement execution and during changes in isometric muscle contraction (e.g., Alegre et al., 2006; Cassim et al., 2000; Crone et al., 1998; Doyle et al., 2005; Kilavik et al., 2012; Omlor et al., 2011; Stančák et al., 1997; Tzagarakis et al., 2010; van Wijk et al., 2009). It is reported for both self-paced and stimulus-triggered movements (Alegre et al., 2003a; Gaetz et al., 2010) as well as for different effectors such as fingers (Gaetz et al., 2010), wrist (Alegre et al., 2006), shoulder (Stančák et al., 2000), foot (Pfurtscheller and Lopes da Silva, 1999a) and tongue (Crone et al., 1998). The drop in beta power lasts as long as the effector is moving (Stančák and Pfurtscheller, 1996; Erbil and Ungan, 2007; Wheaton et al., 2009) and during continuous changes in muscle contraction (Omlor et al., 2011). The beta power increases rapidly if a prepared

A

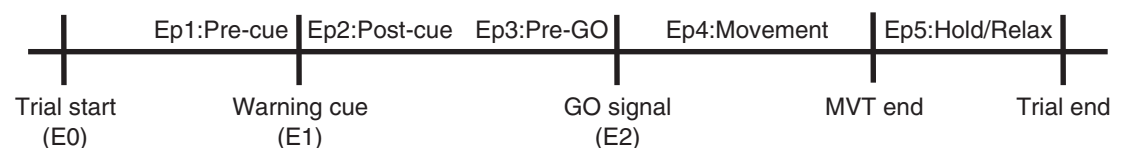

B

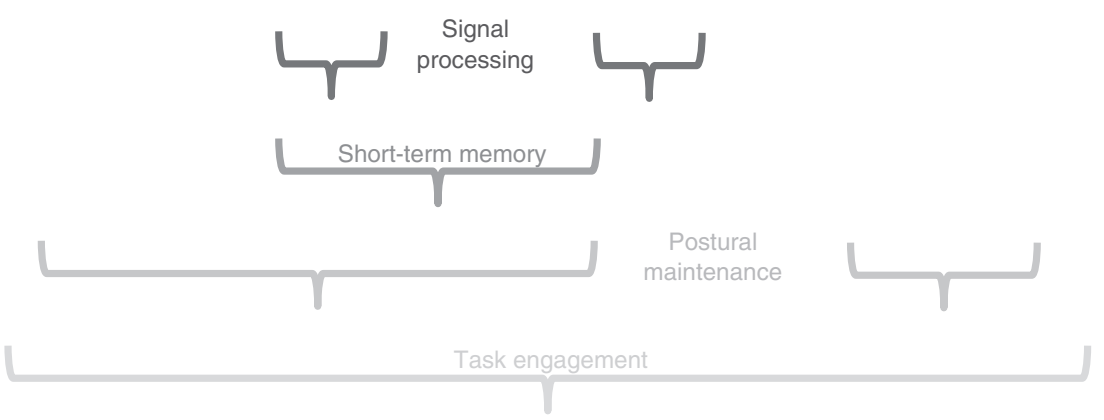

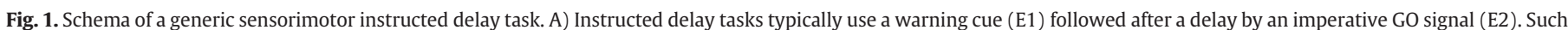

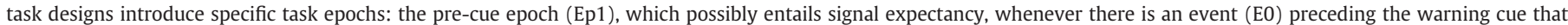

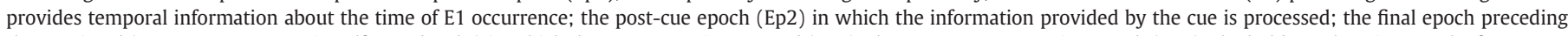

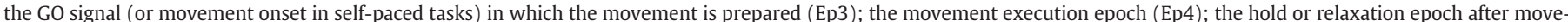

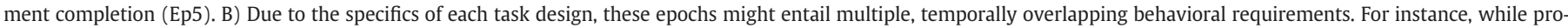

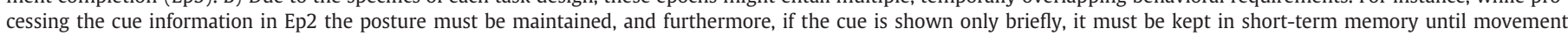
execution after the GO signal. 
movement is not performed, for example after presentation of a NO-GO signal (Alegre et al., 2004; Leocani et al., 2001; Wheaton et al., 2009; Zhang et al., 2008). Furthermore, beta power increases as soon as the contraction or posture become stable (Baker et al., 1999; Spinks et al., 2008; van Elk et al., 2010).

Interestingly, no study showed differences in the drop of beta power during the execution of different types of upper-limb movements. In particular, no difference has been found between rapid and slow index finger movements (Stančák and Pfurtscheller, 1995, 1996), index and four-finger flexion (Salmelin et al., 1995a), ballistic and sustained wrist movements or muscle relaxation (Alegre et al., 2003b), different types of praxis movements (Wheaton et al., 2009), different grip types used to grasp an object or the amount of force used for its manipulation (Pistohl et al., 2012; Stančák et al., 1997). In addition, there was no difference in beta power during the movement whether the subjects focused more on movement speed than on accuracy (Pastötter et al., 2011). Moreover, for stimulus-triggered movements, some studies showed that the time course of the beta power during movement execution and the preceding reaction time (RT) period is not different between simple and choice RT tasks, meaning that the beta power is rather insensitive to the type or amount of information about the forthcoming movement that is provided by the GO signal (Leocani et al., 2001). Even though this observation is consistent for the execution phase, it is more ambiguous for the RT period (Doyle et al., 2005; Tzagarakis et al., 2010). Finally, age has been associated with a consistent decrease in movement-related power, being maximal in adults, suggestive of a maturational phenomenon (Gaetz et al., 2010).

The movement-related power decrease is typically observed bilaterally over sensorimotor areas (e.g. Alegre et al., 2003b; Bai et al., 2005; Doyle et al., 2005; Erbil and Ungan, 2007; Leocani et al., 1997, 2001; Pfurtscheller et al., 1996; Rau et al., 2003; Salmelin and Hari, 1994; Stančák and Pfurtscheller, 1996). In a few cases, its amplitude has a contralateral preponderance (Jurkiewicz et al., 2006; Salmelin et al., 1995a), but there appears to be a consensus on a somatotopic organization of the movement-related power decrease (Crone et al., 1998; Salmelin et al., 1995b; Stančák et al., 2000). The power decrease induced by a foot movement is more medial than the power decrease induced by an index finger movement. However, the precise cortical localization is still not clear. Beta oscillatory activity was found to be mainly attenuated either in the anterior bank of the precentral sulcus (Jasper and Penfield, 1949; Salmelin and Hari, 1994), in the posterior bank of the central sulcus (Jurkiewicz et al., 2006), or both (Papakostopoulos et al., 1980; Sochůrková et al., 2006; Szurhaj et al., 2003).

A change in muscle activity is sufficient, but not necessary, to induce a beta power decrease. It can be elicited, although with reduced amplitude, during motor imagery (McFarland et al., 2000; Nakagawa et al., 2011), movement observation (Babiloni et al., 2002; Koelewijn et al., 2008), passive movement and kinesthetic illusion (Keinrath et al., 2006). During tactile stimulation a power decrease is also observed over the sensorimotor cortex (Cheyne et al., 2003; Gaetz and Cheyne, 2006). Finally, it was confirmed that sensorimotor beta oscillations are functionally related to motor control by showing altered oscillatory activity with motor impairments (for a review, see Leocani and Comi, 2006), and by inducing changes in motor performance with transcranial alternating current stimulation in the beta range above motor cortex (Pogosyan et al., 2009; Joundi et al., 2012).

In summary, the drop in beta power during movement is observed bilaterally, sometimes with a contralateral preponderance. It originates from the sensorimotor cortex and is somatotopically organized, but its exact cortical origin (whether post- or pre-central) is still disputed. Decrease in beta power also occurs when no active muscle contraction is required as during action observation or passive movement. For an active movement, the amplitude of the beta power is insensitive to many experimental factors such as movement type.
The question then arises: what does the decreased beta power during movement execution reflect? Many authors argue that it indicates the activation of the sensorimotor network (Pfurtscheller and Lopes da Silva, 1999b) associated with an increase in corticospinal excitability (Chen et al., 1998) as well as an increase in the fMRI BOLD signal (Formaggio et al., 2008; Stevenson et al., 2011; Yuan et al., 2010). Here, we propose that this hypothesis should be revisited for several reasons. First, it is not clear why the beta power decrease is widespread and sometimes stronger during single-joint movements than during multi-joint reach-to-grasp movements (Stančák et al., 2000), even though converging evidence supports that complex movements require more cortical resources (Ehrsson et al., 2002; Zaepffel and Brochier, 2012). Second, it is not clear why the force parameter does not affect the amplitude of the movement-related power decrease (Pistohl et al., 2012; Stančák et al., 1997), since high forces induce stronger cortical activity than low forces (Cramer et al., 2002; Keisker et al., 2009). To complicate things even more, Rau et al. (2003) showed that the ipsilateral power decrease corresponds to an increase in cortical excitability, consistent with findings that ipsilateral motor cortex is also involved (activated) in unilateral movement execution (Lecas et al., 1986; Vaadia and Cardoso de Oliveira, 2005; van den Berg et al., 2011). However, the ipsilateral power decrease was also interpreted, somewhat paradoxically, as a suppression of mirror movement activity (Jurkiewicz et al., 2006).

To conclude, a clear functional role of the movement-related power decrease cannot be determined from the current literature. Nevertheless, the drop in beta power during movement execution may reflect the conjunction of multiple factors associated with sensory and cognitive aspects of motor control rather than pure motor processes per se (e.g., Müller et al., 2003).

\section{Post-movement beta 'rebound'}

A second consistent modulation is the post-movement beta rebound, which is characterized by a transient and prominent increase in beta power occurring 300 to $1000 \mathrm{~ms}$ after movement end. The magnitude of the beta rebound seems to parallel the speed of the preceding movement (Parkes et al., 2006), although some investigators have reported no difference between slow and rapid movements (Stančák and Pfurtscheller, 1995, 1996). The clearest relationship appears to be with ongoing static EMG activity. In fact, the power of the beta rebound in the arm zone of sensorimotor cortex has been shown to be negatively correlated with static arm EMG activity during the post-movement rebound period (Demandt et al., 2012). However, the beta rebound is also seen in subjects imagining to perform a movement (Pfurtscheller and Solis-Escalante, 2009; Solis-Escalante et al., 2012).

In general, the post-movement beta rebound does not have the same spatial distribution as the preceding beta power decrement (Gaetz et al., 2011). Its cortical generators have been localized in motor areas including primary motor cortex and supplementary motor area (Brovelli et al., 2002; Jurkiewicz et al., 2006; Koelewijn et al., 2008; Neuper and Pfurtscheller, 1996; Salmelin et al., 1995b; Stančák et al., 2000). However, interpretations drawn from electrocorticographical (ECoG) studies seem to converge on the idea that the beta rebound does not arise from a discrete cortical focus, but rather from a distributed cortical network including the whole sensorimotor and premotor area (Crone et al., 1998; Ohara et al., 2000; Pfurtscheller et al., 2003; Sochůrková et al., 2006; Szurhaj et al., 2003; Toro et al., 1994). These results are derived from human experiments. Unfortunately, in monkey studies, the beta rebound would be hard to dissociate from processes related to the post-movement reward and the co-occurrence of these two events greatly compromises the interpretation of beta oscillatory activity during this time period.

One proposal is that the beta rebound reflects an active inhibition of the motor network (Solis-Escalante et al., 2012). The movementevoked potentials in the EMG elicited by transcranial magnetic 
stimulation (TMS) reveal a significant decrease in corticospinal excitability towards the end of the typical rebound period, specifically around 700-1000 ms after movement end (Chen et al., 1998). Several lines of evidence suggest that somatosensory activity is responsible for the postulated inhibition (Cassim et al., 2001; Houdayer et al., 2006; Reyns et al., 2008). Moreover, a treatment with benzodiazepines, known to increase GABA-A receptor-mediated inhibition, increases the resting level of beta oscillations in human sensorimotor cortex (Jensen et al., 2005) and the GABA-level in the motor cortex correlates with the rebound magnitude (Gaetz et al., 2011). However, the net effect of cortical GABA-mediated currents cannot be known with certainty; they can be either depolarizing or hyperpolarizing (Sauer et al., 2012), and disinhibitory as much as inhibitory on corticospinal neurons. The results reported by Feige et al. (2000) are also incompatible with a purely inhibitory function for the beta rebound; they demonstrated a significant increase in corticomuscular coherence in the beta frequency range between motor cortical EEG activity and the flexor digitorum muscle EMG after a phasic finger flexion. The generator of this beta cortico-muscular coherence was localized in primary motor and premotor cortices. The time interval of the enhanced cortico-muscular coherence corresponded to that of the rebound, although the latter comprised a broader range of frequencies. These results indicate that part of the beta spectrum may mediate sensorimotor transmission of signals. This conclusion is also supported by the finding that, following passive limb displacement, the beta rebound disappeared when subjects were functionally deafferented by an ischemic nerve block (Cassim et al., 2001). Certainly, facilitation of sensory influx could proceed in superficial layers of motor cortex with either a net excitation or inhibition occurring concomitantly in deep-layer corticospinal neurons. If this is indeed the case, then beta oscillations could have quite an indirect and rather arbitrary relationship with corticospinal excitability.

An alternative hypothesis is that the post-movement period may be used by the sensorimotor cortex to recalibrate or reset the motor system to new conditions, in order to prepare for a subsequent movement. The remarkable finding of Gaetz and Cheyne (2006), that the beta rebound shows up in the hand motor area after tactile stimulation of lip or toe could reflect a preparatory process for a subsequent hand movement. These authors suggest that the beta power rebound following tactile stimulation may be an OFF response. However, although tactile OFF responses are often observed in the somatosensory cortex, their latencies for finger stimulation do not exceed $140 \mathrm{~ms}$ (Onishi et al., 2010) and they precede by far the beta rebound. To use the words of Gaetz and Cheyne (2006), the primary role of the beta rebound could well be "the ongoing coordination of sensory input and motor output maintained by continuous input from the periphery via somatosensory afferents."

\section{Beta power during static hold}

During episodes of static postural maintenance, especially stable object holding, beta oscillations display a relative increase in power (Baker et al., 1997; Conway et al., 1995; Donoghue et al., 1998; MacKay and Mendonça, 1995; Rougeul et al., 1979; Sanes and Donoghue, 1993), starting at about $300 \mathrm{~ms}$ after stable grasp onset (Spinks et al., 2008). This is not necessarily a net increase over the resting level of beta power as seen in the beta rebound, but a significant increase relative to the decrement observed during the dynamic phase of movement (van Elk et al., 2010). Regarding selectivity, simple 'hook' grips are associated with greater beta power than a precision grip involving the thumb (Spinks et al., 2008), similar to the finding of larger power for meaningless compared to meaningful end posture of the hand holding an everyday-life object (Van Elk et al., 2010).

During static hold, beta oscillations are shown to be significantly coherent and phase synchronized with the EMG of the tonically contracting muscles (Baker et al., 1997). Also, the firing of motor cortical neurons (including pyramidal tract neurons) is partially phase-locked to the beta oscillation (Baker et al., 1997; Denker et al., 2011; Murthy and Fetz, 1992). This suggests that the beta rhythm in motor cortex synchronizes with motor unit activity during static postural maintenance and may partly drive the tonic muscle contraction. However, it is equally possible that muscle reafference is driving cortical activity. Indeed, an analysis using a Granger causality measure revealed directed coherence in both directions, with phase delays close to expected conduction times (Witham et al., 2011). Accordingly, the beta frequency band is compatible with the facilitation of somatosensory-motor loops (i.e., loop times in the general range of $50 \mathrm{~ms}$ ), and the data of Witham et al. (2011) support this possibility. Corticomuscular coherence is also observed during phasic movements, but in a lower frequency range, namely $2-14 \mathrm{~Hz}$ (Feige et al., 2000).

Baker and Baker (2003) found that benzodiazepine administration, which increases GABA-A receptor mediated inhibition in sensorimotor cortex and the power of beta oscillations, reduced beta-band corticomuscular coherence, albeit by a small amount. They interpreted their results as indicating that corticomuscular coherence was maintained at a relatively constant level compared to the large fluctuations in motor cortical beta power. They suggest that the beta-band oscillation "mediates some form of sensorimotor integration between the cortex and the periphery of which coherence is, fortuitously, the appropriate measure" (Baker and Baker, 2003). Spinks et al. (2008) showed an inverse relationship between grasp-type tuning of spiking activity (including pyramidal tract neurons) and beta power during active object hold and postulated that beta oscillations may regularize corticospinal discharge through inhibitory interneurons. At the large-scale cortical level, beta oscillations can synchronize over multiple cortical areas during motor maintenance and carry directional influences as determined by using Granger causality measures from primary somatosensory to inferior posterior parietal cortices and motor cortex (Brovelli et al., 2004). Overall, current literature suggests that beta episodes may allow momentary coupling across multiple cortical areas involved in sensorimotor integration (Lalo et al., 2007; Spinks et al., 2008).

It is easily forgotten that LFP beta power is not continuously high, but usually occurs in bursts ("spindles") at different times during the hold period of grasping tasks (Baker et al., 1997; Murthy and Fetz, 1992, 1996). This property again points toward a sensorimotor 'refreshment' function, rather than a tonic motor drive. Moreover, the inverse LFP-beta/firing-rate correlation demonstrated by Spinks et al. (2008) has a "broad temporal relationship rather than one reflecting a moment-to-moment coupling." These episodes of beta oscillation (and increased corticomuscular coherence) during a stable object hold have been shown to be associated with both enhanced sensory evoked potentials (SEPs), to median nerve stimulation in sensorimotor cortex (Lalo et al., 2007) and enhanced transcortical stretch reflexes (Gilbertson et al., 2005). Seki and Fetz (2012) also showed a relative increase of cutaneous SEP amplitude in sensorimotor cortex during intervals of active holding.

\section{Beta power in earlier epochs of delay tasks}

\section{Pre-cue peak in beta power}

Several recent studies used delay tasks in which a warning cue (E1) is followed by an instructed delay before the imperative GO signal (E2, see Fig. 1). Such task designs introduce additional and distinct task epochs: (Ep1) the pre-cue epoch possibly entailing signal expectancy, (Ep2) the post-cue epoch in which the information provided by the cue is processed while withholding an immediate movement execution, and (Ep3) the final epoch preceding the GO signal (or movement onset in self-paced tasks) in which the movement is prepared. Beta oscillations in sensorimotor cortex are clearly modulated during all these epochs. In this section we discuss pre-cue modulations of beta power, while post-cue and pre-GO/move modulations will be addressed in the following sections. 
It has been shown that sensory cues are preceded by anticipatory activity in motor cortical neurons (Mauritz and Wise, 1986; Confais et al., 2012). It is evident that such activity relies on timing processes, and the moment of cue occurrence can only be efficiently timed whenever there is a relatively short and predictable interval between the cue and the preceding event (scalar property of timing, Gibbon, 1977). In some studies, the subject self-initiated trials by moving to a specified start position, such that there was a well-defined event (E0, see Fig. 1) before cue presentation (Saleh et al., 2010; Takahashi et al., 2011; van Wijk et al., 2009). Two other studies used more complex task designs. In Haegens et al. (2011) two vibrotactile cues were presented in sequence (here denoted E0-E1) to one hand and the monkey had to compare them (during/after E1) in order to determine the correct motor response performed with the other hand after GO (E2). Here we will only consider their recordings from motor cortex contralateral to the active hand. In Kilavik et al. (2012), the event that may best be defined as E0 was a time cue (see Fig. 2C), informing about the duration of the intervals between E0 and the spatial cue (E1), and between E1 and E2 (GO signal). In yet other task designs, the event immediately preceding the warning cue in trial $\mathrm{n}$ was the end of the movement in trial $n-1$, such that the E0-E1 interval corresponded to the inter-trial-interval (Alegre et al., 2004, 2006; Doyle et al., 2005).

Although cued delay tasks are frequently used, only a handful of studies have specifically addressed the pre-cue beta power in sensorimotor areas (Kilavik et al., 2012; Saleh et al., 2010; Takahashi et al., 2011), with a few additional papers showing enough data for us to infer the pre-cue beta power modulations (Alegre et al., 2004, 2006; Doyle et al., 2005; Haegens et al., 2011; van Wijk et al., 2009). Three of the latter portray unmodulated and relatively low beta power in the pre-cue period with respect to other moments in the task (Alegre et al., 2004, 2006; Doyle et al., 2005). They used very long and variable inter-trial-intervals ranging from 6 to $10 \mathrm{~s}$, with the last event (E0) preceding the warning cue being the end of the previous trial. This might be the reason for the flat pre-cue beta power (see, for instance, Fig. 2 in Alegre et al., 2004). The other studies all show beta power to be maximal in the pre-cue epoch, either in most of the interval before the cue (Kilavik et al., 2012; see Fig. 2C), or clearly peaking shortly before or at cue onset (Haegens et al., 2011; Saleh et al., 2010; Takahashi et al., 2011; van Wijk et al., 2009; see Figs. 2A).

An important issue is whether the pre-cue peak in beta power is related to the information provided by the cue. In some studies the subjects knew in advance that the warning cue (E1) essentially only indicated when the imperative GO signal (E2) would be presented. For instance, van Wijk et al. (2009) used blocks of conditions with either $100 \%$ or $50 \%$ (non-predictive) warning cue validity regarding hand selection. They showed that beta power peaked bilaterally shortly before the warning cue also when the cue was known to be non-informative about hand selection. They did not, however, specify
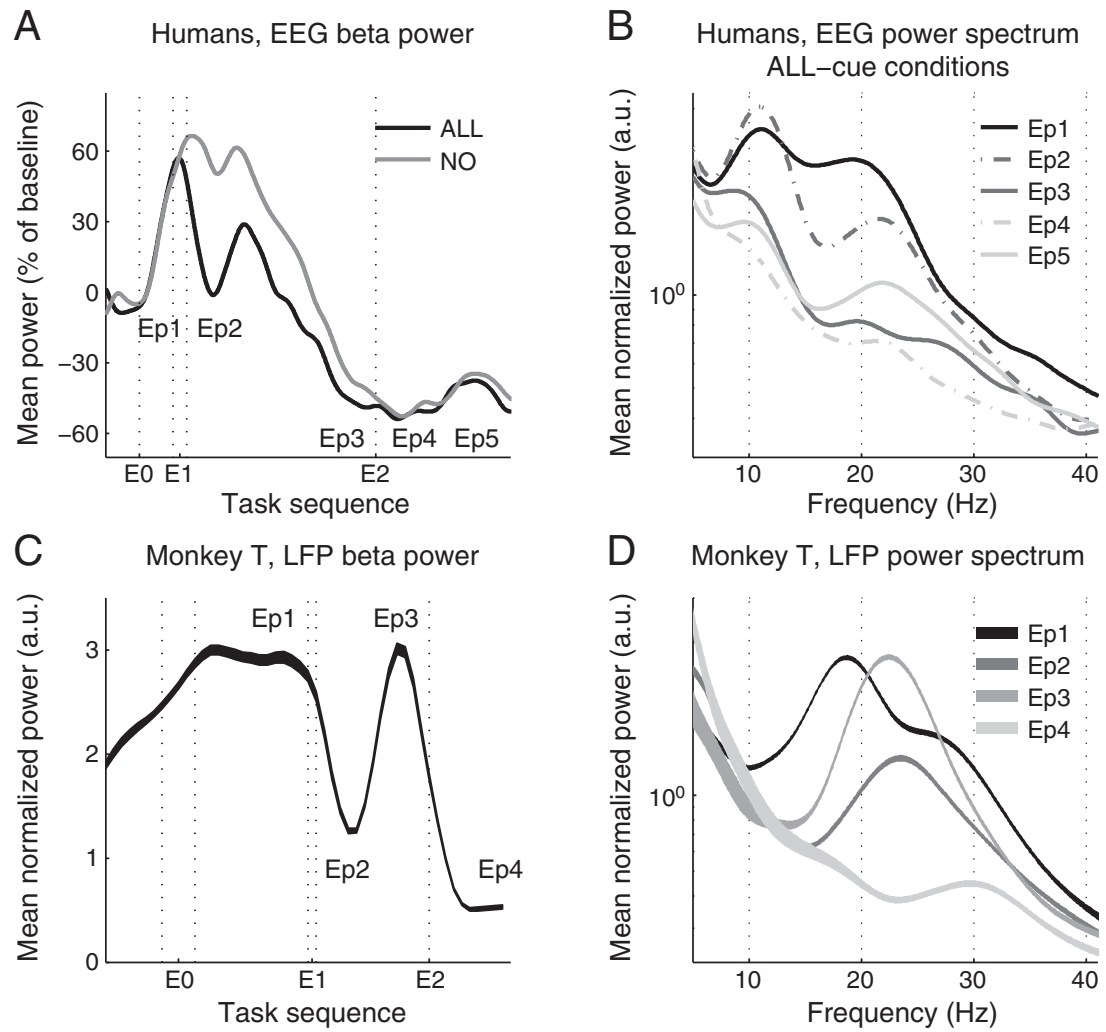

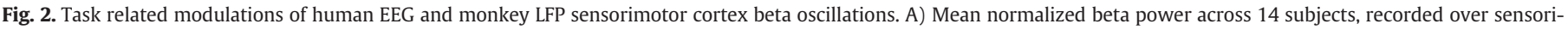

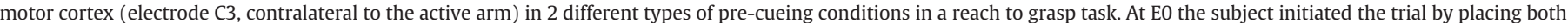

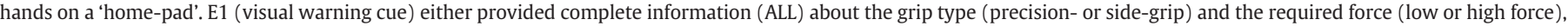

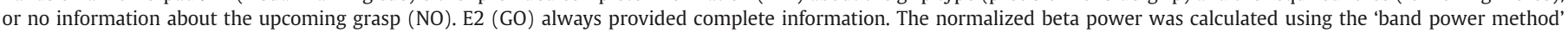

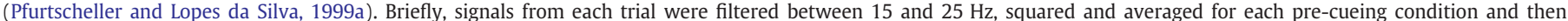

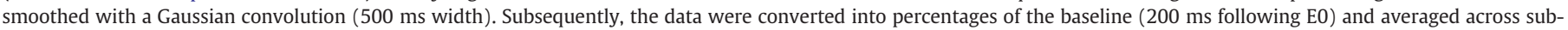

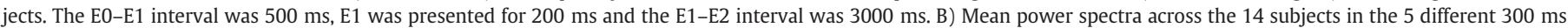

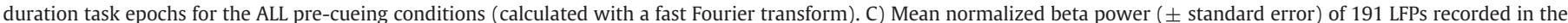

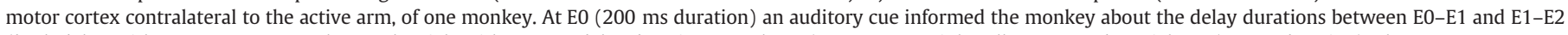

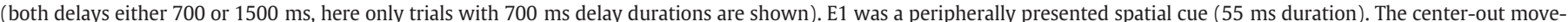

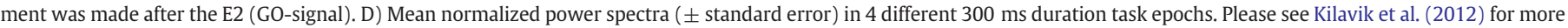
details on the data analysis. Selected task epochs: Ep1-pre-cue; Ep2-post-cue; Ep3-pre-GO; Ep4-movement; Ep5-object hold (only in A-B). Subplots (A-B) are unpublished data from M. Zaepffel and T. Brochier and (C-D) are modified from Kilavik et al. (2012). 
whether there was an absolute difference in the pre-cue beta power in the predictive vs. non-predictive conditions. For the purpose of this review, we specifically tested this in the EEG data presented in Fig. $2 \mathrm{~A}$, in which the active hand was always the same, but different amounts of information about the upcoming grasp was given in the warning cue from trial to trial. We found no significant difference in the contralateral beta power at cue onset when comparing the block in which the warning cue contained no information about the upcoming grasp (NO condition) with the other block having an informative warning cue (ALL condition; analyzed in a window from $-150 \mathrm{~ms}$ to $+50 \mathrm{~ms}$ around cue onset; paired $t$-test across subjects, $p>0.05$ ). However, Saleh et al. (2010) found that the pre-cue beta power started to increase earlier (already before E0) in a more complex color-association task compared with a simpler spatial cueing task, even if the peak power at the relevant warning cue onset was similar for the two tasks (their Fig. 5). Indeed, in the color-association task, E0, which marked the end of a movement placing the cursor at the center of the screen, consisted in the presentation of eight differently colored peripheral targets, thereby providing task-relevant information. This could explain why beta power increased earlier in this task (Saleh et al., 2010). In Kilavik et al. (2012), E0 contained temporal information about E1 (two possible delay durations between E0 and E1). This might be the reason why beta power increased already prior to E0, reaching its maximum just after it (see Fig. 2C). Along this line, a recent study using rhythmic streams of auditory stimuli (Fujioka et al., 2012; see also Arnal, 2012) found beta power in motor areas (as well as in several other areas including auditory cortex) to peak just before each sound event, even if the subjects were only required to passively listen to the rhythmic streams. They propose that this distributed pre-cue increase in beta power provides a mechanism for maintaining predictive timing. It follows that the subsequent increase in beta power also in the epoch preceding the GO signal described in some studies (see below) might have the same origin, reflecting event timing.

As suggested in Fig. 1, additional processes may explain the pre-cue peak in beta power. Could it simply be a beta rebound after E0, since E0 often marks the start of postural maintenance after a movement to initiate the trial? Saleh et al. (2010) provide the most convincing argument that the pre-cue peak in beta power is not merely a post-E0 beta rebound, by showing that the power at the start of the trial modulates differently in the two tasks that differ in complexity, but not in task timing or movement type. Furthermore, it was proposed that increased beta power might reflect the expected maintenance of the current cognitive state, or a low likelihood for needing to process new actions (Engel and Fries, 2010; Jenkinson and Brown, 2011). But according to this view one might rather expect a decrease in beta power in anticipation of warning cues that contain information that can be used for movement planning, which is however rather opposite to what is observed.

Importantly, some studies used the pre-cue epoch as 'baseline' (e.g. van Wijk et al., 2009). According to the specific task design, the baseline beta oscillations might thereby reflect multiple processes, such as post-movement sensorimotor updating, postural maintenance, signal expectancy or more general task timing (see Fig. 3). We would like to stress that the potential complexity of the baseline epoch must be taken into account when interpreting relative modulations in beta power in other task epochs.

Overall, current literature suggests that whenever it is possible to predict the timing of visual cues, the pre-cue beta power in sensorimotor cortex is elevated. This supports previous studies implicating beta oscillations in large-scale visuomotor attentional networks (Roelfsema et al., 1997; Classen et al., 1998), and suggests that beta oscillations can reflect an anticipatory up-regulation of sensorimotor processing beyond somatosensation. Further targeted studies are required to determine whether pre-cue beta increase in sensorimotor cortex reflects the anticipated information content of the cue, its

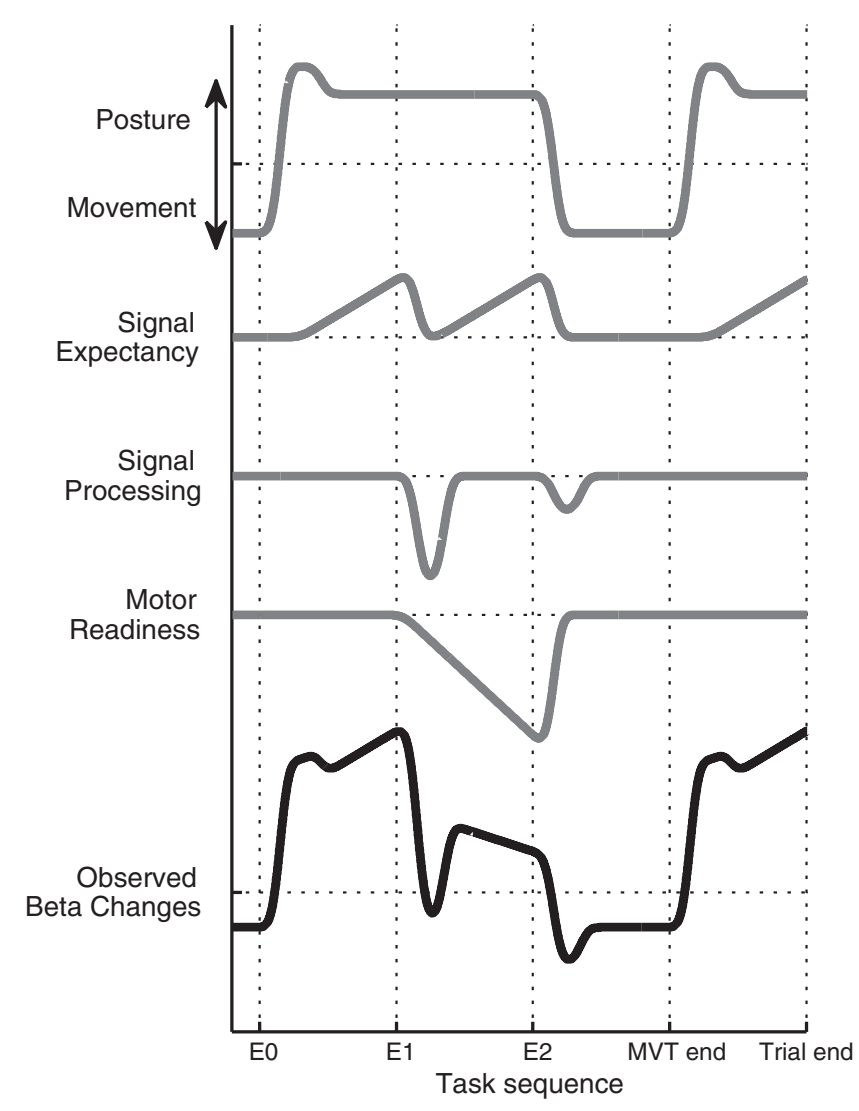

Fig. 3. Ups and downs of beta components. A schematic representation of the main modulations of sensorimotor cortex beta power in the different task epochs that are discussed in this review. The gray traces represent major processes contributing to either increases (upward deflections) or decreases (downward deflections) in beta power. The black trace at the bottom is a simple summation of these processes, and might to some extent reflect the complex modulations of beta power in different task epochs that are observed in EEG or LFP recordings. Depending on the dominance of the different processes, the observed (summed) beta might vary across studies. For instance, the overall degree of power decrease or increase in the pre-GO epoch (before E2) is mainly governed by the counterbalance between motor readiness (power decrease) and GO-signal expectancy (power increase). Please note that for simplicity we have here assumed that the processes in the different traces are independent, which to some degree still remains to be verified experimentally. Only the upper trace combines posture vs. movement, as they are logically opposed, including an additional increase in beta power just after movement end, representing the post movement beta rebound. Furthermore, we have added a small modulation in the signal processing trace also after the GO-signal (E2), even though so far no literature on sensorimotor beta oscillations tried to separate GO-signal processing from movement execution in delay tasks. In addition, a movement is typically made to trigger E0 (trial start), so we also modulate the posture/movement trace around E0. Finally, we have chosen to modulate the signal expectancy trace towards trial end. This is because in most monkey studies this is the time of reward, which is the main goal for the monkey. Modulations of sensorimotor cortex beta oscillations in relation to reward expectancy were not yet studied in monkeys, so the proposed modulation is purely speculative based on the power increases during anticipation of other sensory events (e.g. E1).

temporal predictability and the overall effect of performing a motor task or rather the passive perception of cues.

\section{Post-cue decrease in beta power}

The sensorimotor beta power changes after the presentation of warning cues. First, a few papers describe a short-latency (50-200 ms) transient increase in beta power (O'Leary and Hatsopoulos, 2006; Rubino et al., 2006; see also Williams et al., 2003 for the basal ganglia). This transient increase is phase-locked to the cue (O'Leary and Hatsopoulos, 2006), and generally comparable in timing and duration with the motor cortical visual evoked potentials described by others (Asher et al., 2010; Kilavik et al., 2010; Ledberg et al., 2007). Here we will not discuss further this 
phase-locked transient increase, since it seems distinctly different to the induced changes in beta oscillations.

Rather, a prominent decrease in contralateral sensorimotor beta power (see Fig. 2) is observed in many studies about 300-500 ms after the onset of a warning cue (Alegre et al., 2006; Doyle et al., 2005; Haegens et al., 2011; Kilavik et al., 2012; Klostermann et al., 2007; Pastötter et al., 2011; Saleh et al., 2010; Tzagarakis et al., 2010; van Wijk et al., 2009; see also Klostermann et al., 2007; Williams et al., 2003 for the basal ganglia). This power decrease is distinct and separated from the pre-movement power decrease (described below) by an intervening return towards pre-cue power levels (see Fig. 2A) or even beyond (e.g. Alegre et al., 2006) (see next section). Furthermore, the post-cue power decrease has a relatively fixed timing after the cue, even though not being phase-locked to it, rather than being modulated in timing or magnitude by the duration of the interval preceding the subsequent task event (Fujioka et al., 2012; Kilavik and Riehle, 2010; Kilavik et al., 2012).

The decrease in beta power follows the directionally selective visually evoked responses to the cue (O'Leary and Hatsopoulos, 2006; Kilavik et al., 2010). Thus, beta power remains high (close to the pre-cue level) during the initial visuomotor processing, which is consistent with the proposition that beta oscillations reflect communication within visuomotor networks (Roelfsema et al., 1997; Classen et al., 1998, see previous section). The subsequent power decrease might then reflect early movement preparatory processes, and it is therefore interesting to evaluate whether it is affected by the information content of the warning cue. Indeed, some studies found that the beta power in sensorimotor areas decreased much less after warning cues that contained no useful information for movement preparation (van Wijk et al., 2009, see also Fig. 2A). Williams et al. (2003) recorded from the sub-thalamic nucleus using a similar task than the one used in van Wijk et al. (2009), and found as well that beta power decreased less following non-predictive than predictive warning cues. Furthermore, Tzagarakis et al. (2010) found that the post-cue power decrease scaled with directional uncertainty, being more prominent when uncertainty was minimal. However, Doyle et al. (2005) found a similar post-cue decrease for non-predictive and predictive warning cues in the sensorimotor cortex. Finally, Saleh et al. (2010) found that the post-cue beta power decrease in motor cortex was more prominent in the more complex color association task than in the simpler spatial cueing task (while the pre-cue peak power was rather similar in the two tasks, as mentioned above). This suggests a dependency on the complexity of the sensorimotor transformation process.

We conclude that, whereas a consensus seems to emerge on the existence of a post-cue beta power decrease in sensorimotor cortex, there are still controversies regarding the influence of validity or type of the information provided by the cue (e.g., time until the GO cue, limb selection and/or more specific movement parameters), and whether or not the cue is linked to a subsequent motor act (Fujioka et al., 2012). Finally, even if beta power is low in this epoch, there is still a clear power spectral peak in the beta range, at a somewhat higher peak frequency compared to the pre-cue epoch, which was significant in both the human EEG and monkey LFP data (Figs. 2B, D; see Kilavik et al., 2012 for statistical tests on the monkey LFP data; for the human EEG data we performed a paired $t$-test across subjects, comparing pre- and post-cue peak frequency, epochs Ep1 and Ep2, $p=0.006$ ). This may suggest a slightly more restricted or local origin of the beta oscillations during cue processing and early movement preparation than during cue anticipation, if oscillations of higher frequencies reflect smaller and/or more local networks (Kopell et al., 2000; Miller, 2007; von Stein and Sarnthein, 2000).

\section{Frontal increase in beta power during the delay}

Following the post-cue sensorimotor beta power decrease, the subsequent part of the post-cue epoch is characterized by an increase in beta power. It peaks at about $800 \mathrm{~ms}$ after cue onset, and is distributed enough to be seen not only over sensorimotor cortex (Alegre et al., 2004, 2006; Fischer et al., 2010; see Fig. 2A), but also over the entire frontal lobe (Alegre et al., 2004, 2006; Fischer et al., 2010; Molnár et al., 2008). It seems to be independent of whether there is a preceding post-cue beta power decrease (Alegre et al., 2006; van Wijk et al., 2009; see also Fig. 2A). It is mainly observed bilaterally (Alegre et al., 2006; van Wijk et al., 2009) whereas the preceding post-cue power decrease is mainly contralateral (Doyle et al., 2005; Alegre et al., 2006; van Wijk et al., 2009). Moreover, the post-cue power decrease spans a broader range of frequencies within the beta band than the following power increase (Alegre et al., 2006). Taken together, this novel beta component seems to be distinct, and not merely a 'rebound' back to the pre-cue state subsequent to the post-cue decrease. However, only a few studies have focused so far on this beta modulation, currently making it difficult to interpret its possible functional role.

\section{Pre-movement beta power}

The time epoch that immediately precedes the movement or GO signal is, in most cases, characterized by a gradual decrease in beta power starting approximately 1-2 s before movement onset (e.g. Alegre et al., 2003a; Doyle et al., 2005; Stančák and Pfurtscheller, 1996; van Elk et al., 2010). This gradual decrease reaches a maximum around GO or movement onset (e.g. Doyle et al., 2005). For stimulus-triggered movements, when the GO signal is hardly predictable, the pre-GO power decrease is only weak or absent (Alegre et al., 2003a, 2006; Gaetz et al., 2011; Spinks et al., 2008; but see Alegre et al., 2004). As observed during movement execution (discussed above), the pre-GO/move beta amplitude is rather insensitive to the type of movement for a given effector. There is no difference in amplitude between rapid and slow index finger movements (Stančák and Pfurtscheller, 1995, 1996), ballistic and sustained wrist movements as well as muscle relaxation (Alegre et al., 2003b; Cassim et al., 2000; Toma et al., 2000), different types of praxis movements (Wheaton et al., 2009).

Some factors still influence the amplitude of the pre-GO/move power decrease, in contrast with the power decrease during movement. First, Stančák et al. (1997) showed that the pre-movement power decrease is modulated by load changes opposing a self-paced index movement. Second, Tzagarakis et al. (2010) showed that the pre-GO/ move power decrease is modulated by the uncertainty about the direction of the forthcoming movement. Third, the pre-GO/move power decrease is stronger when the subjects focus more on movement speed than accuracy (Pastötter et al., 2011). Altogether, the pre-GO power decrease seems to be more sensitive to experimental factors than the movement-related power decrease, even though further investigations are still needed, especially to elucidate the conditions in which the amplitude of the pre-GO/move power decrease is correlated with behavioral performance (Perfetti et al., 2011; Tzagarakis et al., 2010).

The precise cortical sources of both the movement-related power decrease and the pre-GO/move power decrease are still uncertain. Nevertheless, both beta components have been localized in the sensorimotor areas (Pfurtscheller et al., 2003; Szurhaj et al., 2003) and have a somatotopic organization (Neuper and Pfurtscheller, 2001; Stančák et al., 2000; Tombini et al., 2009; Wheaton et al., 2008). For upper limb movements, the pre-GO/move power decrease is not as symmetrically distributed between the contralateral and ipsilateral sensorimotor cortices as the movement-related power decrease, but shows a contralateral preponderance. However, this contralateral preponderance occurs only when the moving hand is known in advance (Doyle et al., 2005; Kilner et al., 2005; van Wijk et al., 2009) or once it is selected (Donner et al., 2009). For self-paced movements, the power decrease becomes bilateral right before movement onset, but only for the non-dominant hand (Stancák and Pfurtscheller, 1996). Moreover, it has to be noted that some studies still showed a symmetrical power decrease during 
the entire preparatory period for a non-dominant hand movement (Bai et al., 2005; Nakagawa et al., 2011). In these studies, rather complex movements were performed by the subjects, which may explain the discrepancies with other findings. However, this issue remains to be investigated in more detail.

The pre-GO/move power decrease is considered to reflect an increasing activity in the sensorimotor cortex related to movement preparation (e.g., Kilner et al., 2005; Wheaton et al., 2008). This power decrease seems to be specific for the preparation of a limb movement since it is absent for gaze tracking (Tombini et al., 2009). Movement preparation is a complex operation comprising many physiological processes with different time courses (Jennings and van der Molen, 2005; Requin et al., 1991; Riehle, 2005). The pre-GO/move power decrease may be related to one or several of these processes such as stimulus identification, stimulus-response association (i.e., selection) and motor planning. In tasks where a GO is preceded by a warning cue providing prior information about one or several parameters of the forthcoming movement (e.g., effector, grip type, required force), it has been shown that the contralateral power decrease during this latter part of the preparatory delay is stronger when the moving hand is known in advance. Therefore, this power decrease was attributed to response selection (Doyle et al., 2005; van Wijk et al., 2009), which likely start as early as a few hundred milliseconds after cue presentation and may also be reflected in the cue-related power decrease (see above). Attributing the gradual power decrease before GO to motor planning processes only may be problematic however. First, the type of effector (e.g., left or right hand, foot, shoulder) is the main source of modulation of the pre-GO/move power decrease. Beyond this, the decrease is rather insensitive to the manipulation of other movement parameters in contrast with slow event-related potentials (ERPs) observed during the preparatory delay such as the contingent negative variation (CNV) (see Leuthold et al., 2004 for a review; Zaepffel and Brochier, 2012). Second, the gradual power decrease is still observed when there is uncertainty about the nature of the forthcoming response, i.e. when full and efficient motor planning is not possible (Doyle et al., 2005; van Wijk et al., 2009).

Despite the differences in modulation between the beta power during movement execution and the pre-GO/move power decrease that remain to be clarified, we suggest that both components might be influenced by a common underlying process. Indeed, the beta power decrease is strikingly reminiscent of the long-established decrement in somatosensory responsiveness during movement (Cohen and Starr, 1987; Coquery et al., 1972; Seki and Fetz, 2012). The movement-related decline in the gain of sensory-evoked potentials (SEP) does by far not block sensory responses in sensorimotor cortex (Chapman and Ageranioti-Bélanger, 1991). It may, however, serve to keep the large increase in reafference during movements from 'overloading' sensorimotor processing. The decline in SEP amplitude starts prior to movement onset by about $100 \mathrm{~ms}$ for triggered movements (Cohen and Starr, 1987), but during an instructed delay it starts earlier (Seki and Fetz, 2012). The reduction in SEP amplitude during the preparatory period is limited to the motor cortex (Seki and Fetz, 2012). Self-paced movements have only been studied by Hazemann et al. (1975). They reported a significant decline in SEP amplitude starting about $400 \mathrm{~ms}$ prior to movement onset. Moreover, they found that a volitional movement was associated with a large-scale sensory dampening; both auditory and somatosensory pathways were similarly affected (including stimulation of either side of the body). A passive movement also elicits a decline in SEP amplitude (Coquery et al., 1972; Seki and Fetz, 2012), and a reduction in beta power (Müller et al., 2003). Unfortunately, testing the SEP amplitude has never extended through the time interval of the post-movement beta rebound. However, the data of Cohen and Starr (1987) show a tantalizing increase of SEP amplitude at about 300 ms post-movement compared to rest, in all three of their subjects. What is really lacking is a systematic within-subject test of the putative correlation between movement-related beta power decrease/rebound and SEP amplitude.

Finally, while there is a consensus about the power decrease during movement execution, the pre-GO/move power decrease is not systematically observed. In particular, in some monkey studies the beta power actually increases before GO (Haegens et al., 2011; Kilavik et al., 2012; see also Hwang and Andersen, 2009 for the parietal reach region). In others, the power remains rather unmodulated during the later parts of the preparatory delay (Rubino et al., 2006; Spinks et al., 2008). Overall, none of the monkey data shows a convincing early pre-movement decrease in beta power, up to 1-2 s before movement onset as in humans. This cannot be due to a technical issue, e.g. a difference between EEG and LFP, since for instance Saleh et al. (2010) recorded LFPs in their human patient, and still observed a pre-GO power decrease (see also Sochůrková et al., 2006; Szurhaj et al., 2003).

It might be that the pre-GO/move power increase is mediated by the same underlying process as the increase preceding the warning cue, reflecting an anticipation of the GO signal. Thus, the pre-GO power increase, which to our knowledge is only significantly observed in some monkey studies, might reflect enhanced event timing in the over-trained animals, when they are confronted with a task with predictable delay durations (e.g., Haegens et al., 2011; Hwang and Andersen, 2009; Kilavik et al., 2012). The fact that the slope of this increase in power preceding the GO signal depends on the delay duration (Kilavik and Riehle, 2010) strongly argues for such a relation to timing processes (see also Fujioka et al., 2012). Enhanced timing may also explain the peak in parietal pre-movement beta power during a self-paced task, in which the monkey self-adjusted the movement onset to fall within a relatively strict temporal window in order to optimize the amount of reward (Hwang and Andersen, 2009).

\section{Discussion}

We reviewed the ups and downs of sensorimotor beta oscillations in selected task epochs, identifying separate sensorimotor beta components that are differently modulated by specific experimental factors. Here we suggest that a given component may be the result of several processes, which may overlap in time and affect in parallel the power of the sensorimotor beta oscillations. In Fig. 3, we summarize the resulting observed beta power modulations (lower black trace), which may be produced by the combination of different functional processes. Each contribution by such a process is illustrated by a separate line (gray traces). For instance, we described above that the power increase before or at cue onset might reflect timing processes (cue expectancy), but this does not necessarily exclude other processes related, for instance, to postural maintenance or those underlying the beta rebound. Preceding GO or movement onset, a power increase can sometimes be observed in monkeys. We suggest that this pre-GO power increase reflects more dominant timing processes related to GO expectancy. In humans, however, a pre-GO/move power decrease is quite systematic and is often, but not exclusively, related to selection and motor planning. Interestingly, it is also observed during motor imagery, tactile stimulation, passive movements, and action observation. The main factor eliciting the power decrease both before and during movement might be a functional decrease in somatosensory responsiveness for the efficient unfolding of the movement (e.g. Seki and Fetz, 2012). Also the rebound after the movement can be observed in many different task protocols. As we discussed above, it may be related to a sensorimotor resetting function, with heightened sensorimotor transmission and integration.

Furthermore, the power increase at $800 \mathrm{~ms}$ after cue onset is sometimes above the baseline level (e.g., Alegre et al., 2006) or sometimes the power remains at a low level until GO (e.g., Nakagawa et al., 2011; Tzagarakis et al., 2010). Since this component is rather weak and surrounded by the strong post-cue power decrease and pre-GO 
modulations, we suggest that it is particularly affected by the overlap of different processes which is most prominent when the preparatory delay is short (Nakagawa et al., 2011; Tzagarakis et al., 2010).

Several studies already illustrate the concept of overlap of various functional processes constituting the beta components. For example, Trenner et al. (2008) presented a vibrotactile stimulus preceding the GO signal by a fixed delay. The typical pre-GO power decrease was not observed but "overwritten" by a beta increase elicited by the tactile stimulus, making the process(es) that usually elicit(s) a power decrease in this task epoch invisible. Moreover, the beta rebound elicited by median nerve stimulation is reduced or absent when the stimulation is made during different types of actual or imagined hand movements (Pfurtscheller et al., 2002; Salenius et al., 1997; Schnitzler et al., 1997). Finally, it has also been reported that within the beta band several co-occurring beta rhythms might be distinguished in some subjects, for instance in high beta $(>20 \mathrm{~Hz})$ and a low beta rhythm $(<20 \mathrm{~Hz})$ (Kilavik et al., 2012; Salmelin et al., 1995a; Szurhaj et al., 2003). When a broad frequency band is analyzed, these rhythms may be mixed together being a source of high variability and thus discrepancies between studies.

It is noteworthy that the increase in beta power during a static hold posture starts in parallel with the beta rebound after movement end. Some aspects of both beta episodes would appear to be the same. Indeed, we typically hold an object or maintain a posture after terminating a given movement. In the framework of the hypothesis that beta oscillations facilitate corticocortical transmission to motor cortex, the common factor could be the upscaling of somatosensory responsiveness after a stable posture is achieved. Increased sensorimotor communication would serve the purpose of resetting or updating the internal model of current body status. The determinant of cortical sensory responsiveness appears to be both the descending motor signal ("efference copy") and the peripheral afferent feedback itself (Chapman et al., 1988); together they suppress reafference at several stages, a self-regulating gain control mechanism. If motor cortical beta power is indeed linked to sensorimotor transmission, then different levels of beta power either during a stable posture or after movement end could be dependent on the current degree of such a gain control. This may explain the negative correlation between beta power and EMG activity (Demandt et al., 2012), and the different beta power magnitude for hook and precision grips (Spinks et al., 2008)

Finally, what should not be overlooked is that short-term memory is an implicit aspect of pre-cued motor tasks (see Fig. 1). In many task designs the warning cue is only briefly presented, followed by a delay before a non-informative GO signal. We currently have no relevant information from sensorimotor areas to assess relationships between memory processes and beta power increases or decreases, and therefore did not attempt to include memory in our schema in Fig. 3. Short-term memory has been associated with increases of beta power in occipital, parietal, and (pre-)frontal areas (e.g., Deiber et al., 2007; Onton et al., 2005; Pesaran et al., 2002; Tallon-Baudry et al., 2004). It would be important to compare oscillatory activity in sensorimotor areas, for instance, between conditions in which the cue was either available during the whole delay until movement onset or turned off after a short time, requiring short-term memory during the preparatory delay before $\mathrm{GO}$.

In conclusion, we demonstrate the composite nature of beta oscillations in sensorimotor cortex. As illustrated in Fig. 3, the contribution of different functional processes simulates the great majority of beta components described in the current literature. We show that even though a decrease in beta power may be related to an activation state, this does not imply that an increase is related to an "idling" state, as often proposed, but rather to another mode of information transmission/processing. After reviewing the large body of experimental literature, it becomes obvious that many processes might influence the beta-band activity, explaining why the functional significance of the different beta components is still poorly understood. The main obstacle is the difficulty in comparing data across studies since the experimental context is often extremely different. We hope that this review provides a guideline for future studies to better understand the multitude of functional roles of sensorimotor beta oscillations, possibly underlying large-scale communication between sensorimotor and other areas and the periphery.

\section{Acknowledgments}

Grants: ANR-GRASP (A.R.), AXA Research Fund (B.E.K.); Fondation de la Recherche Medicale (B.E.K.), Les Treilles Fondation (M.Z.).

The authors thank Thomas Brochier for many interesting discussions and for critically reading the manuscript.

\section{References}

Alavi, M., Dostrovsky, J.O., Hodaie, M., Lozano, A.M., Hutchison, W.D., 2013. Spatial extent of beta oscillatory activity in and between the subthalamic nucleus and substantia nigra pars reticulata of Parkinson's disease patients. Exp. Neurol. 245, 60-71 (this issue).

Alegre, M., Gurtubay, I.G., Labarga, A., Iriarte, J., Malanda, A., Artieda, J., 2003a. Alpha and beta oscillatory changes during stimulus-induced movement paradigms: effect of stimulus predictability. Neuroreport 14, 381-385.

Alegre, M., Labarga, A., Gurtubay, I.G., Iriarte, J., Malanda, A., Artieda, J., 2003b. Movement-related changes in cortical oscillatory activity in ballistic, sustained and negative movements. Exp. Brain Res. 148, 17-25.

Alegre, M., Gurtubay, I.G., Labarga, A., Iriarte, J., Valencia, M., Artieda, J., 2004. Frontal and central oscillatory changes related to different aspects of the motor process: a study in go/no-go paradigms. Exp. Brain Res. 159, 14-22.

Alegre, M., Imirizaldu, L., Valencia, M., Iriarte, J., Arcocha, J., Artieda, J., 2006. Alpha and beta changes in cortical oscillatory activity in a go/no go randomly-delayedresponse choice reaction time paradigm. Clin. Neurophysiol. 117, 16-25.

Arnal, L.H., 2012. Predicting "when" using the motory system's beta-band oscillations. Front. Hum. Neurosci. 6, 225.

Asher, I., Zinger, N., Yanai, Y., Israel, Z., Prut, Y., 2010. Population-based corticospinal interactions in macaques are correlated with visuomotor processing. Cereb. Cortex 20, 241-252.

Babiloni, C., Babiloni, F., Carducci, F., Cincotti, F., Cocozza, G., Del percio, C., Moretti, D.V. Rossini, P.M., 2002. Human cortical electroencephalography (EEG) rhythms during the observation of simple aimless movement: a high-resolution EEG study. Neuroimage 17, 559-572.

Bai, O., Mari, Z., Vorbach, S., Hallett, M., 2005. Asymetric spatiotemporal patterns of eventrelated desynchronization preceding voluntary sequential finger movements: a highresolution EEG study. Clin. Neurophysiol. 116, 1213-1221.

Baker, M.R., Baker, S.N., 2003. The effect of diazepam on motor cortical oscillations and corticomuscular coherence studied in man. J. Physiol. 546, 931-942.

Baker, S.N., Olivier, E., Lemon, R.N., 1997. Coherent oscillations in monkey motor cortex and hand muscle EMG show task-dependent modulation. J. Physiol. 501, 225-241.

Baker, S.N., Kilner, J.M., Pinches, E.M., Lemon, R.N., 1999. The role of synchrony and oscillation in the motor output. Exp. Brain Res. 128, 109-117.

Berger, H., 1929. Über das elektrenkephalogramm des menschen. Eur. Arch. Psychiatry Clin. Neurosci. 87, 527-570.

Brovelli, A., Battaglini, P.P., Naranjo, J.R., Budai, R., 2002. Medium-range oscillatory network and the $20-\mathrm{Hz}$ sensorimotor induced potential. Neuroimage $16,130-141$.

Brovelli, A., Ding, M., Ledberg, A., Chen, Y., Nakamura, R., Bressler, S.L., 2004. Beta oscillations in a large-scale sensorimotor cortical network: directional influences revealed by Granger causality. Proc. Natl. Acad. Sci. U. S. A. 101, 9849-9854.

Brunel, N., Wang, X.J., 2003. What determines the frequency of fast network oscillations with irregular neural discharges? I. Synaptic dynamics and excitationinhibition balance. J. Neurophysiol. 90, 415-430.

Buschman, T.J., Miller, E.K., 2007. Top-down versus bottom-up control of attention in the prefrontal and posterior parietal cortices. Science 315, 1860-1862.

Buzsáki, G., 2006. Rhythms of the Brain. Oxford University Press, New York (NY)

Cassim, F., Szurhaj, W., Sediri, H., Devos, D., Bourriez, J., Poirot, I., Derambure, P., Defebvre, L., Guieu, J., 2000. Brief and sustained movements: differences in event-related (de) synchronization (ERD/ERS) patterns. Clin. Neurophysiol. 111, 2032-2039.

Cassim, F., Monaca, C., Szurhaj, W., Bourriez, J.L., Defebvre, L., Derambure, P., Guieu, J.D., 2001. Does post-movement beta synchronization reflect an idling motor cortex? Neuroreport 12, 3859-3863.

Cassim, F., Labyt, E., Devos, D., Defebvre, L., Destée, A., Derambure, P., 2002. Relationship between oscillations in the basal ganglia and synchronization of cortical activity. Epileptic Disord. 4 (S3), S31-S45.

Chapman, C.E., Ageranioti-Bélanger, S.A., 1991. Discharge properties of neurons in the hand area of primary somatosensory cortex in monkeys in relation to the performance of an active tactile discrimination task. I. Areas 3b and 1. Exp. Brain Res. 87, 319-339.

Chapman, C.E., Jiang, W., Lamarre, Y., 1988. Modulation of lemniscal input during conditioned arm movements in the monkey. Exp. Brain Res. 72, 316-334.

Chen, R., Yaseen, Z., Cohen, L.G., Hallett, M., 1998. Time course of corticospinal excitability in reaction time and self-paced movements. Ann. Neurol. 44, 317-325. 
Cheyne, D., Gaetz, W., Garnero, L., Lachaux, J.P., Ducorps, A., Schwartz, D., Varela, F.J., 2003. Neuromagnetic imaging of cortical oscillations accompanying tactile stimulation. Cogn. Brain Res. 17, 599-611.

Classen, J., Gerloff, C., Honda, M., Hallett, M., 1998. Intergrative visuomotor behavior is associated with interregionally coherent oscillations in the human brain. J. Neurophysiol. 79, 1567-1573.

Cohen, L.G., Starr, A., 1987. Localization, timing and specificity of gating of somatosensory evoked potentials during active movement in man. Brain 110, 451-467.

Confais, J., Kilavik, B.E., Ponce-Alvarez, A., Riehle, A., 2012. On the anticipatory pre-cue activity in motor cortex. J. Neurosci. 32, 15359-15368.

Conway, B.A., Halliday, D.M., Farmer, S.F., Shahani, U., Maas, P., Weir, A.I., Rosenberg, J.R., 1995. Synchronization between motor cortex and spinal motoneuronal pool during the performance of a maintained motor task in man. J. Physiol. 489, 917-924.

Coquery, J.M., Coulemance, M., Leron, M.C., 1972. Modifications des potentiels évoqués corticaux somesthésiques durant des mouvements actifs et passifs chez l'homme. Electroencephalogr. Clin. Neurophysiol. 33, 269-276.

Courtemanche, R., Lamarre, Y., 2005. Local field potential oscillations in primate cerebellar cortex: synchronization with cerebral cortex during active and passive expectancy. J. Neurophysiol. 93, 2039-2052.

Courtemanche, R., Fujii, N., Graybiel, A.M., 2003. Synchronous, focally modulated betaband oscillations characterize local field potential activity in the striatum of awake behaving monkeys. J. Neurosci. 23, 11741-11752.

Cramer, S.C., Weisskoff, R.M., Schaechter, J.D., Nelles, G., Foley, M., Finklestein, S.P., Rosen, B.R., 2002. Hum. Brain Mapp. 16, 197-205.

Crone, N.E., Miglioretti, D.L., Gordon, B., Sieracki, J.M., Wilson, M.T., Uematsu, S., Lesser, R.P., 1998. Functional mapping of human sensorimotor cortex with electrocorticographic spectral analysis. I. Alpha and beta event-related desynchronization. Brain 121, 2271-2299.

Deiber, M.P., Missonnier, P., Bertrand, O., Gold, G., Fazio-Costa, L., Ibanez, V., Giannakopoulos, P., 2007. Distinction between perceptual and attentional processing in working memory tasks: a study of phase-locked and induced oscillatory brain dynamics. J. Cogn. Neurosci. 19, 158-172.

Demandt, E., Mehring, C., Vogt, K., Schulze-Bonhage, A., Aertsen, A., Ball, T., 2012. Reaching movement onset- and end-related characteristics of EEG spectral power modulations. Front. Neurosci. 6, 65.

Denker, M., Roux, S., Lindén, H., Diesmann, M., Riehle, A., Grün, S., 2011. The local field potential reflects surplus spike synchrony. Cereb. Cortex 21, 2681-2695.

Donner, T.H., Siegel, M., Fries, P., Engel, A.K., 2009. Buildup of choice-predictive activity in human motor cortex during perceptual decision making. Curr. Biol. 19, 1581-1585.

Donoghue, J.P., Sanes, J.N., Hatsopoulos, N.G., Gaál, G., 1998. Neural discharge and local field potential oscillations in primate motor cortex during voluntary movements. J. Neurophysiol. 79, 159-173.

Doyle, L.M.F., Yarrow, K., Brown, P., 2005. Lateralization of event-related beta desychronization in the EEG during pre-cued reaction time tasks. Clin. Neurophysiol. 116, 1879-1888.

Ehrsson, H.H., Kuhtz-Buschbeck, J.P., Forssberg, H., 2002. Brain regions controlling nonsynergistic versus synergistic movement of the digits: a functional magnetic resonance imaging study. J. Neurosci. 22, 5074-5080.

Engel, A.K., Fries, P., 2010. Beta-band oscillations - signalling the status quo? Curr. Opin. Neurobiol. 20, 156-165.

Erbil, N., Ungan, P., 2007. Changes in the alpha and beta amplitudes of the central EEG during the onset, continuation, and offset of long-duration repetitive hand movements. Brain Res. 1169, 44-56.

Feige, B., Aertsen, A., Kristeva-Feige, R., 2000. Dynamic synchronization between multiple cortical motor areas and muscle activity in phasic voluntary movements. J. Neurophysiol. 84, 2622-2629.

Fischer, T., Langner, R., Diers, K., Brocke, B., Birbaumer, N., 2010. Temporo-spatial dynamics of event-related EEG beta activity during the initial contingent negative variation. PLoS One 5 (9) (Sep 2, pii: e12514).

Fogelson, N., Williams, D., Tijssen, M., van Bruggen, G., Speelman, H., Brown, P., 2006. Different functional loops between cerebral cortex and the subthalmic area in Parkinson's disease. Cereb. Cortex 16, 64-75.

Formaggio, E., Storti, S.F., Avesani, M., Cerini, R., Milanese, F., Gasparini, A., Acler, M., Pozzi Mucelli, R., Fiaschi, A., Manganotti, P., 2008. EEG and FMRI coregistration to investigate the cortical oscillatory activities during finger movement. Brain Topogr. $21,100-111$.

Fujioka, T., Trainor, L.J., Large, E.W., Ross, B., 2012. Internalized timing of isochronous sounds is represented in neuromagnetic Beta oscillations. J. Neurosci. 32, 1791-1802.

Gaetz, W., Cheyne, D., 2006. Localization of sensorimotor cortical rhythms induced by tactile stimulation using spatially filtered MEG. Neuroimage 30, 899-908.

Gaetz, W., Macdonald, M., Cheyne, D., Snead, O.C., 2010. Neuromagnetic imaging of movement-related cortical oscillations in children and adults: age predicts postmovement beta rebound. Neuroimage 51, 792-807.

Gaetz, W., Edgar, J.C., Wang, D.J., Roberts, T.P.L., 2011. Relating MEG measured motor cortical oscillations to resting $\gamma$-aminobutyric acid (GABA) concentration. Neuroimage 55, 616-621.

Gibbon, J., 1977. Scalar expectancy theory and Weber's law in animal timing. Psychiatry Rev. 84, 279-325.

Gilbertson, T., Lalo, E., Doyle, L., Di Lazzaro, V., Cioni, B., Brown, P., 2005. Existing motor state is favored at the expense of new movement during $13-35 \mathrm{~Hz}$ oscillatory synchrony in the human corticospinal system. J. Neurosci. 25, 7771-7779.

Haegens, S., Nácher, V., Hernández, A., Luna, R., Jensen, O., Romo, R., 2011. Beta oscillations in the monkey sensorimotor network reflect somatosensory decision making. Proc. Natl. Acad. Sci. U. S. A. 108, 10708-10713.
Hazemann, P., Audin, G., Lille, F., 1975. Effect of voluntary self-paced movements upon auditory and somatosensory evoked potentials in man. Electroencephalogr. Clin. Neurophysiol. 39, 247-254.

Houdayer, E., Labyt, E., Cassim, F., Bourriez, J.L., Derambure, P., 2006. Relationship between event-related beta synchronization and afferent inputs: analysis of finge movement and peripheral nerve stimulations. Clin. Neurophysiol. 117, 628-636.

Hwang, E.J., Andersen, R.A., 2009. Brain control of movement execution onset using local field potentials in posterior parietal cortex. J. Neurosci. 29, 14363-14370.

Jasper, H., Penfield, W., 1949. Electrocorticograms in man: effect of voluntary movement upon the electrical activity of the precentral gyrus. Arch. Psychiatry Zeitschr. Neurol. 83, 163-174.

Jenkinson, N., Brown, P., 2011. New insights into the relationship between dopamine, beta oscillations and motor function. Trends Neurosci. 34, 611-618.

Jennings, J.R., van der Molen, M.W., 2005. Preparation for speeded action as a psychophysiological concept. Psychol. Bull. 131, 434-459.

Jensen, O., Goel, P., Kopell, N., Pohja, M., Hari, R., Ermentrout, B., 2005. On the human sensorimotor-cortex beta rhythm: sources and modeling. Neuroimage 26 , 347-355.

Joundi, R.A., Jenkinson, N., Brittain, J.-S., Aziz, T.Z., Brown, P., 2012. Driving oscillatory activity in the human cortex enhances motor performance. Curr. Biol. 22, 403-407.

Jurkiewicz, M.T., Gaetz, W.C., Bostan, A.C., Cheyne, D., 2006. Post-movement beta rebound is generated in motor cortex: evidence from neuromagnetic recordings. Neuroimage 32, 1281-1289.

Keinrath, C., Wriessnegger, S., Müller-Putz, G.R., Pfurtscheller, G., 2006. Post-movement beta synchronization after kinesthetic illusion, active and passive movements. Int. J. Psychophysiol. 62, 321-327.

Keisker, B., Hepp-Reymond, M.C., Blickenstorfer, A., Meyer, M., Kollias, S.S., 2009. Differential force scaling of fine-graded power grip force in the sensorimotor network. Hum. Brain Mapp. 30, 2453-2465.

Kilavik, B.E., Riehle, A., 2010. Timing structures neuronal activity during preparation for action. In: Coull, J.T. (Ed.), Attention and Time (Nobre AC). Oxford UP, Oxford, pp. 257-271.

Kilavik, B.E., Confais, J., Ponce-Alvarez, A., Diesmann, M., Riehle, A., 2010. Evoked potentials in motor cortical local field potentials reflect task timing and behavioral performance. J. Neurophysiol. 104, 2338-2351.

Kilavik, B.E., Ponce-Alvarez, A., Trachel, R., Confais, J., Takerkart, S., Riehle, A., 2012 Context-Related Frequency Modulations of Macaque Motor Cortical LFP Beta Oscillations. Cereb. Cortex 22 (9), 2148-2159 (Sep).

Kilner, J., Bott, L., Posada, A., 2005. Modulation in the degree of synchronization during ongoing oscillatory activity in the human brain. Eur. J. Neurosci. 21, 2547-2554.

Klostermann, F., Nikulin, V.V., Kühn, A.A., Marzinzik, F., Wahl, M., Pogosyan, A., Kupsch, A., Schneider, G.H., Brown, P., Curio, G., 2007. Task-related differential dynamics of EEG alpha- and beta-band synchronization in cortico-basal motor structures. Eur. J. Neurosci. 25, 1604-1615.

Koelewijn, T., van Schie, H.T., Bekkering, H., Oostenveld, R., Jensen, O., 2008. Motor-cortical beta oscillations are modulated by correctness of observed action. Neuroimage 40 767-775.

Kopell, N., Ermentrout, G.B., Whittington, M.A., Traub, R.D., 2000. Gamma rhythms and beta rhythms have different synchronization properties. Proc. Natl. Acad. Sci. U. S. A. 97, 1867-1872.

Lalo, E., Gilbertson, T., Doyle, L., Di Lazzaro, V., Cioni, B., Brown, P., 2007. Phasic increases in cortical beta activity are associated with alterations in sensory processing in the human. Exp. Brain Res. 177, 137-145.

Lalo, E., Thobois, S., Sharott, A., Polo, G., Mertens, P., Pogosyan, A., Brown, P., 2008. Patterns of bidirectional communication between cortex and basal ganglia during movement in patients with Parkinson disease. J. Neurosci. 28, 3008-3016.

Lecas, J.C., Requin, J., Anger, C., Vitton, N., 1986. Changes in neuronal activity of the monkey precentral cortex during preparation for movement. J. Neurophysiol. 56, 1680-1702.

Ledberg, A., Bressler, S.L., Ding, M., Coppola, R., Nakamura, R., 2007. Large-scale visuomotor integration in the cerebral cortex. Cereb. Cortex 17, 44-62.

Leocani, L., Comi, G., 2006. Movement-related desynchronization in neuropsychiatric disorders. Prog. Brain Res. 159, 351-366.

Leocani, L., Toro, C., Manganotti, P., Zhuang, P., Hallett, M., 1997. Event-related coherence and event-related desynchronization/synchronization in the $10 \mathrm{~Hz}$ and $20 \mathrm{~Hz}$ EEG during self-paced movements. Electroencephalogr. Clin. Neurophysiol. 104, 199-206.

Leocani, L., Toro, C., Zhuang, P., Gerloff, C., Hallett, M., 2001. Event-related desynchronization in reaction time paradigms: a comparison with event-related potentials and corticospinal excitability. Clin. Neurophysiol. 112, 923-930.

Leuthold, H., Sommer, W., Ulrich, R., 2004. Preparing for action: inferences from CNV and LRP. J. Psychophysiol. 18, 77-88.

Litvak, V., Jha, A., Eusebio, A., Oostenveld, R., Foltynie, T., Limousin, P., Zrinzo, L., Hariz, M.I., Friston, K., Brown, P., 2011. Resting oscillatory cortico-subthalamic connectivity in patients with Parkinson's disease. Brain 134, 359-374.

MacKay, W.A., Mendonça, A.J., 1995. Field potential oscillatory bursts in parietal cortex before and during reach. Brain Res. 704, 167-174.

Marsden, J.F., Limousin-Dowsey, P., Ashby, P., Pollak, P., Brown, P., 2001. Subthalamic nucleus, sensorimotor cortex and muscle interrelationships in Parkinson's disease. Brain 124, 378-380.

Mauritz, K.H., Wise, S.P., 1986. Premotor cortex of the rhesus monkey: neuronal activity in anticipation of predictable environmental events. Exp. Brain Res. 61, 229-244.

McFarland, D.J., Miner, L.A., Vaughan, T.M., Wolpaw, J.R., 2000. Mu and beta topographies during motor imagery and actual movements. Brain Topogr. 12, 177-186.

Miller, R., 2007. Theory of the normal waking EEG: from single neurones to waveforms in the alpha, beta and gamma frequency ranges. Int. J. Psychophysiol. 64 $18-23$. 
Molnár, M., Csuhaj, R., Gaál, Z.A., Czigler, B., Ulbert, I., Boha, R., Kondákor, I., 2008. Spectral characteristics and linear-nonlinear synchronization changes of different EEC frequency bands during the CNV. Psychophysiology 45, 412-419.

Müller, G.R., Neuper, C., Rupp, R., Keinrath, C., Gerner, H.J., Pfurtscheller, G., 2003. Event-related beta EEG changes during wrist movements induced by functional electrical stimulation of forearm muscles in man. Neurosci. Lett. 340, 143-147.

Murthy, V.N., Fetz, E.E., 1992. Coherent 25- to 35-Hz oscillations in the sensorimotor cortex of behaving monkeys. Proc. Natl. Acad. Sci. U. S. A. 89, 5670-5674.

Murthy, V.N., Fetz, E.E., 1996. Oscillatory activity in sensorimotor cortex of awake monkeys: synchronization of local field potentials and relation to behavior. J. Neurophysiol. 76, 3949-3967.

Nakagawa, K., Aokage, Y., Fukuri, T., Kawahara, Y., Hashizume, A., Kurisu, K., Yuge, L., 2011. Neuromagnetic beta oscillation changes during motor imagery and motor execution of skilled movements. Neuroreport 22, 217-222.

Nauhaus, I., Busse, L., Carandini, Ringach, D.L., 2009. Stimulus contrast modulates functional connectivity in visual cortex. Nat. Neurosci. 12, 70-76.

Neuper, C., Pfurtscheller, G., 1996. Post-movement synchronization of beta rhythms in the EEG over the cortical foot area in man. Neurosci. Lett. 216, 17-20.

Neuper, C., Pfurtscheller, G., 2001. Evidence for distinct beta resonance frequencies in human EEG related to specific sensorimotor cortical areas. Clin. Neurophysiol. 112, 2084-2097.

O'Leary, J.G., Hatsopoulos, N.G., 2006. Early visuomotor representations revealed from evoked local field potentials in motor and premotor cortical areas. J. Neurophysiol. $96,1492-1506$

Ohara, S., Ikeda, A., Kunieda, T., Yazawa, S., Baba, K., Nagamine, T., Taki, Hashimoto N., Mihara, T., Shibasaki, H., 2000. Movement-related change of electrocorticographic activity in human supplementary motor area proper. Brain 123, 1203-1215.

Omlor, W., Patino, L., Mendez-Balbuena, I., Schulte-Mönting, J., Kristeva, R., 2011 Corticospinal beta-range coherence is highly dependent on the pre-stationary motor state. J. Neurosci. 31, 8037-8045.

Onishi, H., Oyama, M., Soma, T., Kubo, M., Kirimoto, H., Murakami, H., Kameyama, S., 2010 Neuromagnetic activation of primary and secondary somatosensory cortex following tactile-on and tactile-off stimulation. Clin. Neurophysiol. 121, 588-593.

Onton, J., Delorme, A., Makeig, S., 2005. Frontal midline EEG dynamics during working memory. Neuroimage 27, 341-356.

Papakostopoulos, D., Crow, H.J., Newton, P., 1980. Spatiotemporal characteristics of intrinsic evoked and event-related potentials in the human cortex. In: Pfurtscheller, G., Lopes da Silva, F., Petsche, H. (Eds.), Rhythmic EEG activities and cortical functioning. Elsevier, Amsterdam, pp. 179-200.

Parkes, L.M., Bastiaansen, M.C.M., Norris, D.G., 2006. Combining EEG and fMRI to investigate the post-movement beta rebound. Neuroimage 29, 685-696.

Pastötter, B., Berchtold, F., Bäuml, K.H., 2012. Oscillatory correlates of controlled speedaccuracy tradeoff in a response-conflict task. Hum. Brain Mapp. 33 (8), 1834-1849 (Aug).

Perfetti, B., Moisello, C., Landsness, E.C., Kvint, S., Pruski, A., Onofrj, M., Tononi, G. Ghilardi, M.F., 2011. Temporal evolution of oscillatory activity predicts performance in a choice-reaction time reaching task. J. Neurophysiol. 105, 18-27.

Pesaran, B., Pezaris, J.S., Sahani, M., Mitra, P.P., Andersen, R.A., 2002. Temporal structure in neuronal activity during working memory in macaque parietal cortex. Nat Neurosci. 5, 805-811.

Pfurtscheller, G., Lopes da Silva, F.H., 1999a. Event-related EEG/MEG synchronization and desynchronization: basic principles. Clin. Neurophysiol. 110, 1842-1857.

Pfurtscheller, G., Lopes da Silva, F.H., 1999b. Functional meaning of event-related desynchronization (ERD) and synchronization (ERS), In: Pfurtscheller, G. Lopes Da Silva, F.H. (Eds.), Event-Related Desynchronization, revised edition. : Handbook of Electroencephalography and Clinical Neurophysiology, vol. 6. Elsevier, Amsterdam, pp. 51-65.

Pfurtscheller, G., Solis-Escalante, T., 2009. Could the beta rebound in the EEG be suitable to realize a "brain switch"? Clin. Neurophysiol. 120, 24-29.

Pfurtscheller, G., Stančák Jr., A., Neuper, C., 1996. Post-movement beta synchronization. A correlate of an idling motor area? Electroencephalogr. Clin. Neurophysiol. 98, 281-293.

Pfurtscheller, G., Woertz, M., Müller, G., Wriessnegger, S., Pfurtscheller, K., 2002. Contrasting behavior of beta event-related synchronization and somatosensory evoked potential after median nerve stimulation during finger manipulation in man. Neurosci. Lett. 323, 113-116.

Pfurtscheller, G., Graimann, B., Huggins, J.E., Levine, S.P., Schuh, L.A., 2003. Spatiotemporal patterns of beta desynchronization and gamma synchronization in corticographic data during self-paced movement. Clin. Neurophysiol. 114, 1226-1236.

Pistohl, T., Schulze-Bonhage, A., Aertsen, A., Mehring, C., Ball, T., 2012. Decoding natura grasp types from human ECoG. Neuroimage 59, 248-260.

Pogosyan, A., Gaynor, L.D., Eusebio, A., Brown, P., 2009. Boosting cortical activity at beta-band frequencies slows movement in humans. Curr. Biol. 19, 1637-1641.

Rau, C., Plewnia, C., Hummel, F., Gerloff, C., 2003. Event-related desynchronization and excitability of the ipsilateral motor cortex during simple self-paced finger movements. Clin. Neurophysiol. 114, 1819-1826.

Ray, S., Maunsell, J.H., 2010. Differences in gamma frequencies across visual cortex restrict their possible use in computation. Neuron 67, 885-896.

Requin, J., Brener, J., Ring, C., 1991. Preparation for action. In: Jennings, J.R., Coles, M.G.H. (Eds.), Handbook of Cognitive Psychophysiology: Central and Autonomic Nervous System Approaches. Wiley, New York, pp. 357-448.

Reyns, N., Houdayer, E., Bourriez, J.L., Blond, S., Derambure, P., 2008. Post-movement beta synchronization in subjects presenting with sensory deafferentation. Clin Neurophysiol. 119, 1335-1345

Riehle, A., 2005. Preparation for action: one of the key functions of the motor cortex. In: Vaadia, E. (Ed.), Motor cortex in voluntary movements (Riehle A). CRC Press, Boca Raton, pp. 213-240.
Roelfsema, P.R., Engel, A.K., König, P., Singer, W., 1997. Visuomotor integration is associated with zero time-lag synchronization among cortical areas. Nature 385, $157-161$

Rougeul, A., Bouyer, J.J., Dedet, L., Debray, O., 1979. Fast somato-parietal rhythms during combined focal attention and immobility in baboon and squirrel monkey. Electroencephalogr. Clin. Neurophysiol. 46, 310-319.

Rubino, D., Robbins, K.A., Hatsopoulos, N.G., 2006. Propagating waves mediate information transfer in the motor cortex. Nat. Neurosci. 9, 549-1557.

Saleh, M., Reimer, J., Penn, R., Ojakangas, C.L., Hatsopoulos, N.G., 2010. Fast and slow oscillations in human primary motor cortex predict oncoming behaviorally relevant cues. Neuron 65, 461-471.

Salenius, S., Schnitzler, A., Salmelin, R., Jousmäki, V., Hari, R., 1997. Modulation of human cortical rolandic rhythms during natural sensorimotor tasks. Neuroimage 5, 221-228.

Salmelin, R., Hari, R., 1994. Spatiotemporal characteristics of sensorimotor neuromagnetic rhythms related to thumb movement. Neuroscience 60, 537-550.

Salmelin, R., Forss, N., Knuutila, J., Hari, R., 1995a. Bilateral activation of the human somatomotor cortex by distal hand movements. Electroencephalogr. Clin. Neurophysiol. 95, 444-452.

Salmelin, R., Hämäläinen, M., Kajola, M., Hari, R., 1995b. Functional segregation of movement-related rhythmic activity in the human brain. Neuroimage 2, 237-243.

Sanes, J.N., Donoghue, J.P., 1993. Oscillations in local field potentials of the primate motor cortex during voluntary movement. Proc. Natl. Acad. Sci. U. S. A. 90, 4470-4474.

Sauer, J.F., Strüber, M., Bartos, M., 2012. Interneurons provide circuit-specific depolarization and hyperpolarization. J. Neurosci. 32, 4224-4229.

Schnitzler, A., Salenius, S., Salmelin, R., Jousmäki, V., Hari, R., 1997. Involvement of primary motor cortex in motor imagery: a neuromagnetic study. Neuroimage 6, 201-208.

Seki, K., Fetz, E.E., 2012. Gating of sensory input at spinal and cortical levels during preparation and execution of voluntary movement. J. Neurosci. 32, 890-902.

Siegel, M., Donner, T.H., Engel, A.K., 2012. Spectral fingerprints of large-scale neuronal interactions. Nat. Rev. Neurosci. 13, 121-134

Sochůrková, D., Rektor, I., Jurák, P., Stančák, A., 2006. Intracerebral recording of cortical activity related to self-paced voluntary movements: a Bereitschaftspotential and eventrelated desynchronization/synchronization. SEEG study. Exp. Brain Res. 173, 637-649.

Solis-Escalante, T., Müller-Putz, G.R., Pfurtscheller, G., Neuper, C., 2012. Cue-induced beta rebound during withholding of overt and covert foot movement. Clin. Neurophysiol. 123, 1182-1190.

Spinks, R.L., Kraskov, A., Brochier, T., Umilta, M.A., Lemon, R.N., 2008. Selectivity for grasp in local field potential and single neuron activity recorded simultaneously from M1 and F5 in the awake macaque monkey. J. Neurosci. 28, 10961-10971.

Stančák, A., Pfurtscheller, G., 1995. Desynchronization and recovery of $\beta$ rhythms during brisk and slow self-paced finger movements in man. Neurosci. Lett. 196, 21-24.

Stančák, A., Pfurtscheller, G., 1996. Event-related desynchronisation of central betarhythms during brisk and slow self-paced finger movements of dominant and nondominant hand. Cogn. Brain Res. 4, 171-183.

Stančák, A., Riml, A., Pfurtscheller, G., 1997. The effect of external load on movementrelated changes of the sensorimotor EEG rhythms. Electroencephalogr. Clin. Neurophysiol. 102, 495-504.

Stančák, A., Feige, B., Lücking, C.H., Kristeva-Feige, R., 2000. Oscillatory cortical activity and movement-realted potentials in proximal and distal movements. Clin. Neurophysiol. 111, 636-650.

Stevenson, C.M., Brookes, M.J., Morris, P.G., 2011. $\beta$-Band correlates of the fMRI BOLD response. Hum. Brain Mapp. 32, 182-197.

Szurhaj, W., Derambure, P., Labyt, E., Cassim, F., Bourriez, J.L., Isnard, J., Guieu, J.D., Mauguière, F., 2003. Basic mechanisms of central rhythms reactivity to preparation and execution of a voluntary movement: a stereoelectroencephalographic study. Clin. Neurophysiol. 1, 107-119.

Takahashi, K., Saleh, M., Penn, R.D., Hatsopoulos, N.G., 2011. Propagating waves in human motor cortex. Front. Hum. Neurosci. 5, 40.

Tallon-Baudry, C., Mandon, S., Freiwald, W.A., Kreiter, A.K., 2004. Oscillatory synchrony in the monkey temporal lobe correlates with performance in a visual short-term memory task. Cereb. Cortex 14, 713-720.

Toma, K., Nagamine, T., Yazawa, S., Terada, K., Ikeda, A., Honda, M., Oga, T., Shibasaki, H., 2000. desynchronization and synchronization of central 20-Hz rhythms associated with voluntary muscle relaxation: a magnetoencephalographic study. Exp. Brain Res. 134, 417-425.

Tombini, M., Zappasodi, F., Zollo, L., Pellegrino, G., Cavallo, G., Tecchio, F., Guglielmelli, E., Rossini, P.M., 2009. Brain activity preceding a 2D manual catching task. Neuroimage 47, 1735-1746

Toro, C., Deuschl, G., Thatcher, R., Sato, S., Kufta, C., Hallett, M., 1994. Event-related desynchronization and movement-related cortical potentials on the ECoG and EEG. Electroencephalogr. Clin. Neurophysiol. 93, 380-389.

Trenner, M.U., Heekeren, H.R., Bauer, M., Rössner, K., Wenzel, R., Villringer, A., Fahle, M., 2008. What happens in between? Human oscillatory brain activity related to crossmodal spatial cueing. PLoS One 3, e1467.

Tsang E.W., Hamani, C., Moro, E., Mazzella, F. Poon, Y., Lozano, A.M., Chen, R., 2010. Involvement of the human pedunculopontine nucleus region in voluntary movements. Neurology 75, 950-959.

Tsang, E.W., Hamani, C., Moro, E., Mazzella, F., Lozano, A.M., Hodaie, M., Yeh, I.J., Chen, R., 2012. Movement related potentials and oscillatory activities in the human internal globus pallidus during voluntary movements. J. Neurol. Neurosurg. Psychiatry 83, 91-97.

Tzagarakis, C., Ince, N.F., Leuthold, A.C., Pellizzer, G., 2010. Beta-band activity during motor planning reflects response uncertainty. J. Neurosci. 30, 11270-11277.

Vaadia, E., Cardoso de Oliveira, S., 2005. Neuronal representations of bimanual movements. In: Riehle, A., Vaadia, E. (Eds.), Motor cortex in voluntary movements. CRC Press, Boca Raton, pp. 109-140. 
Van den Berg, F.E., Swinnen, S.P., Wenderoth, 2011. Excitability of the motor cortex ipsilateral to the moving body side depends on spatio-temporal task complexity and hemispheric specialization. PLoS One 6, e17742.

van Elk, M., van Schie, H.T., van den Heuvel, R., Bekkering, H., 2010. Semantics in the motor system: motor-cortical Beta oscillations reflect semantic knowledge of end-postures for object use. Front. Hum. Neurosci. 4, 8 (Feb 9).

van Wijk, B.C.M., Daffertshofer, A., Roach, N., Praamstra, P., 2009. A role of beta oscillatory synchrony in biasing response competition. Cereb. Cortex 19, 1294-1302.

von Stein, A., Sarnthein, J., 2000. Different frequencies for different scales of cortical integration: from local gamma to long range alpha/theta synchronization. Int. J. Psychophysiol. 38, 301-313.

Wheaton, L., Carpenter, M., Mizelle, J.C., Forrester, L., 2008. Preparatory band specific premotor cortical activity differentiates upper and lower extremity movement. Exp. Brain Res. 184, 121-126.

Wheaton, L., Fridman, E., Bohlhalter, S., Vorbach, S., Hallett, M., 2009. Left parietal activation related to planning, executing and suppressing praxis hand movements. Clin. Neurophysiol. 120, 980-986.
Whittington, M.A., Traub, R.D., Kopell, N., Ermentrout, B., Buhl, E.H., 2000. Inhibitionbased rhythms: experimental and mathematical observations on network dynamics. Int. J. Pschophysiol. 38, 315-336.

Williams, D., Kühn, A., Kupsch, A., Tijssen, M., van Bruggen, G., Speelman, H., Hotton, G. Yarrow, K., Brown, P., 2003. Behavioural cues are associated with modulations of synchronous oscillations in the human subthalamic nucleus. Brain 126, 1975-1985.

Witham, C.L., Riddle, C.N., Baker, M.R., Baker, S.N., 2011. Contributions of descending and ascending pathways to corticomuscular coherence in humans. J. Physiol. 589, 3789-3800.

Yuan, H., Liu, T., Szarkowski, R., Rios, C., Ashe, J., He, B., 2010. Negative covariation between task-related responses in alpha/beta-band activity and BOLD in human sensorimotor cortex: an EEG and fMRI study of motor imagery and movements. Neuroimage 49, 2596-2606.

Zaepffel, M., Brochier, T., 2012. Planning of visually-guided reach-to-grasp movements: inference from reaction time and contingent negative variation (CNV). Psychophysiology 49, 17-30.

Zhang, Y., Chen, Y., Bressler, S.L., Ding, M., 2008. Response preparation and inhibition: the role of the cortical sensorimotor beta rhythm. Neuroscience 156, 238-246. 